\title{
Estimation of currents using SARAL/AltiKa in the coastal regions of India
}

\author{
A. Chaudhary, N. Agarwal, R. Sharma
}

Oceanic Sciences Division, Atmospheric and Oceanic Sciences Group, EPSA.

Space Applications Centre (ISRO), Ahmedabad - 380015, India

(aditya.osd, neeraj, rashmi)@sac.isro.gov.in

Commission VI, WG VI/4

KEY WORDS: Coastal current, Altimeter, Indian coast

\begin{abstract}
:
The present study explores the possibility of deriving the across track currents along the Indian coastal region from SARAL/AltiKa mission. The across track surface geostrophic currents obtained from along track SARAL altimeter data are directly compared (qualitatively) with high frequency (HF) radar observations of surface currents in the Bay of Bengal. The velocity component from $\mathrm{HF}$ radar which is perpendicular to the altimeter tracks is considered. Since the ageostrophic velocity contribution is ignored for the moment, the surface geostrophic currents SARAL compare well only under low wind conditions. Due to high along track resolution of SARAL there are large variations in velocity which are not captured by the HF radar observations. In general, the magnitude and variations in surface currents derived from SARAL altimeter are comparable with HF radar observations.
\end{abstract}

\section{INTRODUCTION}

Coastal currents as well as tides are useful to understand the coastal dynamics helping not only in various coastal applications such as fishing, navigation of ships but also important for coastal engineering such as construction of bridges, docks, etc. Indian coastal currents are divided into two major currents West Indian Coastal Current in the Arabian Sea and East Indian coastal currents in Bay of Bengal. These currents are responsible for the exchange of the water masses between the Arabian Sea and Bay of Bengal maintaining the hydrological balance. These currents have a seasonal cycle and vary from region to region. In this study we try to investigate the coastal currents by the use of satellite based altimeter

Satellite altimeter is an active radar sensor which measures the range of the surface below it (nadir) by sending short radar pulses with known power and measuring the time delay between the transmitted and the received signal (two way travel time) with high accuracy. Thus sea-surface height is the primary parameter that is derived from the altimeter. Global ocean coverage with high temporal and spatial scale has made altimeter an important tool for studying sea surface heights and its variations. It is the only satellite instrument which is capable of measuring the surface geostrophic currents globally and repeatedly. In the open ocean regions the currents are mainly geostrophic therefore altimeters have been in use to study large scale circulation of the global oceans (Johnson, 2007, Sikhakolli, 2013).

Most of the altimeters eg., Geosat, ERS-1/2, TOPEX/Poseidon, Jason-2 and Envisat, so far have worked at Ku band $(\sim 13 \mathrm{GHz})$ frequency. SARAL/AltiKa, an Indo-French joint mission, launched in the year 2013operates at Ka band ( $\sim 35 \mathrm{GHz})$ with wide bandwidth $(\sim 500 \mathrm{MHz})$. Working at this frequency has an advantage that it provides higher vertical and horizontal resolution. Coastal contaminations are seen as the perturbation to the theoretical Brown model (Brown, 1977) of the return pulse shape, as the ground footprint (radius $\sim 7 \mathrm{~km}$ at $1 \mathrm{~Hz}$ sampling) approaches or leaves the shoreline. Operational datasets distributed by various agencies are mostly meant for open ocean studies. Satellite altimeter and radiometer observations are perturbed near the land, which lead to absence of data in this important part of the ocean. However, altimeter and radiometer also make measurements for coastal oceans, which contain valuable information. Due to the high demand of the above mentioned parameters in the coastal regions, it is quite imperative to make a feasibility study towards exploiting SARAL/AltiKa data for deriving SSH, wind speed and wave height information in the Indian region. AltiKa offers unique opportunity to derive these parameters for the coastal region due to its improved signal-to-noise ratio and small footprint because of high pulse repetition frequency.

Since large scale currents are nearly geostrophic in nature, hence their velocities can be calculated from pressure gradient force from the pressure gradient on an equi-geopotential surface. Surface currents can thus be calculated by measuring the variations of the sea level from the equipotential at sea surface i.e. marine geoid. If geoid is known to a sufficient accuracy then this makes the study of global surface geostrophic currents possible through this technique. However, the geoid is still not known with a very high accuracy at smaller scales; hence mean sea surface (constructed using data from various altimetric missions) is used as the reference surface. Hence what we finally use to compute current is the SSHA which is sea level deviation with respect to this mean sea surface. As a consequence of this, surface current computed using this SSHA data is also surface current anomaly and not the absolute surface current.

In this study we have made use of SARAL/AltiKa 1-Hz SSHA data to compute the currents along the eastern coast of India, near Chennai region. Computed currents have been compared with the HF Radar data and their seasonality have been studied. Objective of this study is to assess the potential of AltiKa in providing the accurate measurements of coastal currents. 


\section{DATA USED AND STUDY AREA}

We have made use of the $1-\mathrm{Hz}$ SARAL/AltiKa data made available by the CNES as Interim Geophysical data Records (IGDR) product data for this purpose (SARAL/AltiKa Handbook, 2012). Along with the AltiKa data, HF Radar data provided by Indian National Centre for Ocean Information Services (INCOIS) have been also used in this study. The period of analysis corresponds to October, 2013 (cycle \# 9) through September, 2014 (cycle \# 18). Study region is Chennai coast along the east coast of India. Reason for choosing this area is availability of HF Radar data. In this region, there are 8 tracks (both ascending and descending) of AltiKa which are passing through the areal coverage of HF Radar data. Study region along with the radar coverage and AltiKa tracks are shown in Fig. 1. A total of five SARAL tracks coincide within the domain of HF radar coverage in the Bay of Bengal off Chennai Coast between longitude $79.7 \mathrm{E}$ to $81.5 \mathrm{E}$ and latitude $10.7 \mathrm{~N}$ to $12.7 \mathrm{~N}$.

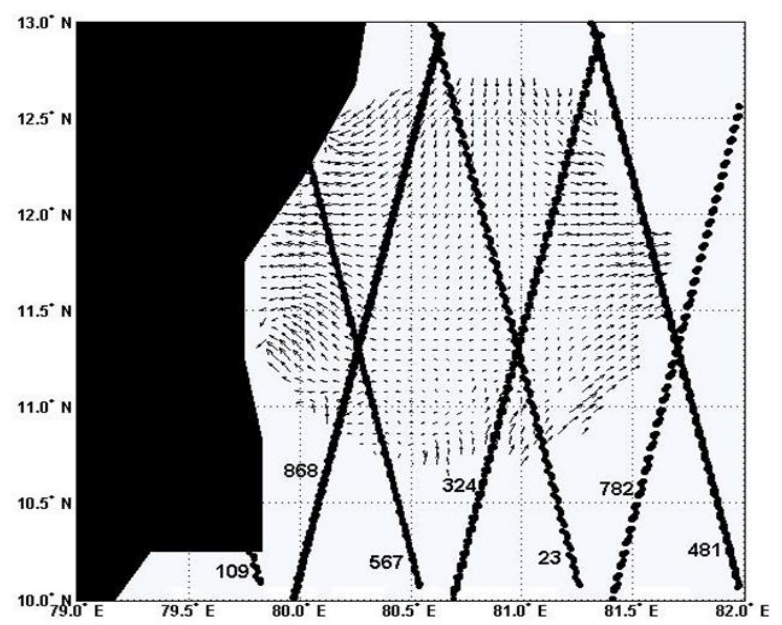

Figure 1. SARAL AltiKA satellite tracks (solid black lines) and HF radar spatial coverage off Chennai coast in the Bay of Bengal.

\section{METHODOLOGY}

Along-track SARAL/AltiKa 1-Hz measurements of SSHA from IGDR products have been used for computing the surface currents. The SSHA from the IGDR product is free from geophysical errors and tidal signals. However there is a lot of noise and large discontinuities that are required to be filtered out. Any value of SSHA larger than five standard deviations (computed based on 20 year SSHA data) is not considered. This is a crude check to filter out large noisy signal and in future it is planned to use a more sophisticated method.

Away from the equator, ocean surface current can be computed from the along-track sea-surface slope using the geostrophic relation (Fu and Cazenave, 2001):

$$
f u=-g \partial h / \partial y
$$

where $u$ is the surface velocity normal to the track (positive eastward), $g$ is gravitational acceleration, $f$ is the Coriolis parameter, $y$ is the along-track distance, and $h$ is the SSHA. This implies that ocean surface geostrophic currents are associated with a sea-level slope across the current.

The above calculation gives only the cross-track component of the residual flow. In many altimetric studies, we assume that the flow is isotropic so that the variance of the cross-track component is taken as representative of the variance of the total surface velocity. This isotropic approximation is valid for a turbulent field, but fluctuations become anisotropic in the presence of mean shear, close to bathymetry, or at larger scales and in the equatorial regions ( $\beta$ effect) where the zonal fluctuations tend to dominate meridional fluctuations. Another point is that the direction of the cross-track component changes with the curvature of the ground track: the component measures more zonal variability near the equator while the part caused by meridional flow becomes equal or larger at high latitudes. The geostrophic relation is a good first-order approximation for estimating the flow field. For comparison the velocity component from HF radar is projected on to the geostrophic velocity component from SARAL AltiKa.

\section{RESULTS AND DISCUSSION}
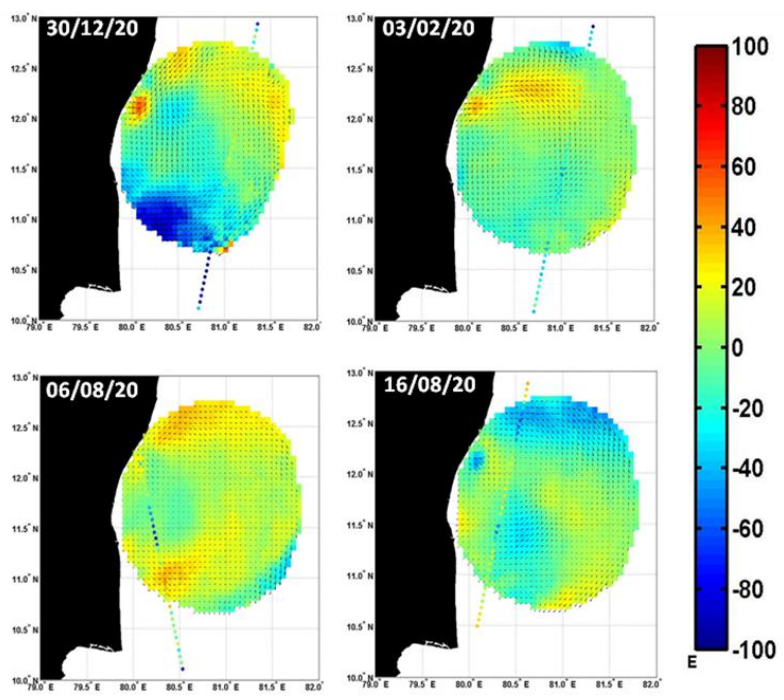

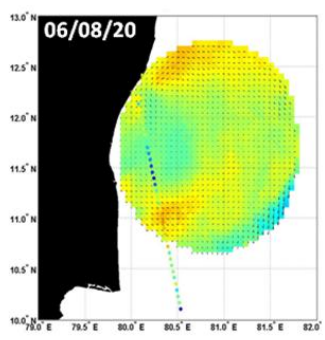

Figure.2 Comparison of Altimeter derived geostrophic velocities with HF radar observations in the Bay of Bengal off Chennai coast: Contours of HF radar velocity (along track component) overlaid with along track geostrophic velocity from SARAL AltiKA

Figure 2 show the altimeter derived geostrophic currents overlaid (as dots) over the HF radar currents for four different time periods. The vector indicates the direction of the currents from from HF radar. It must be noted that for the moment the tidal and other ageostrophic contributions in the HF radar velocities have not been filtered out, so there is likely to be a mismatch in some of the places where ageostrophy dominates. During December (Figure -2 top left panel) the currents along the coast are mainly oriented in the southward direction. This is a typical feature during this season when the East India Coastal currents (EICC) flow from North Bay to south the all along the eastern coast in a very narrow channel all the way up to the south eastern Arabian Sea. The along track velocities from altimeter seems to capture the north south gradient as seen in the HF radar. The negative component in the southern part of the HF radar coverage matches pretty well and the velocity component and it becomes positive as we move along track 
towards north. Similarly during February altimeter derived velocities compare well with the HF radar. The range during this season is between $\pm 40 \mathrm{~cm} / \mathrm{s}$ and the same variation is faithfully captured by altimeter. During August (bottom left Figure.2) the high magnitude in the southern part of track over the HF radar coverage region is nicely captured, however the negative velocities are overestimated between $11.2 \mathrm{~N}$ to $12.7 \mathrm{~N}$. Overall, the range and variation in the altimeter derived geostrophic velocity matches well with HF radar observations.
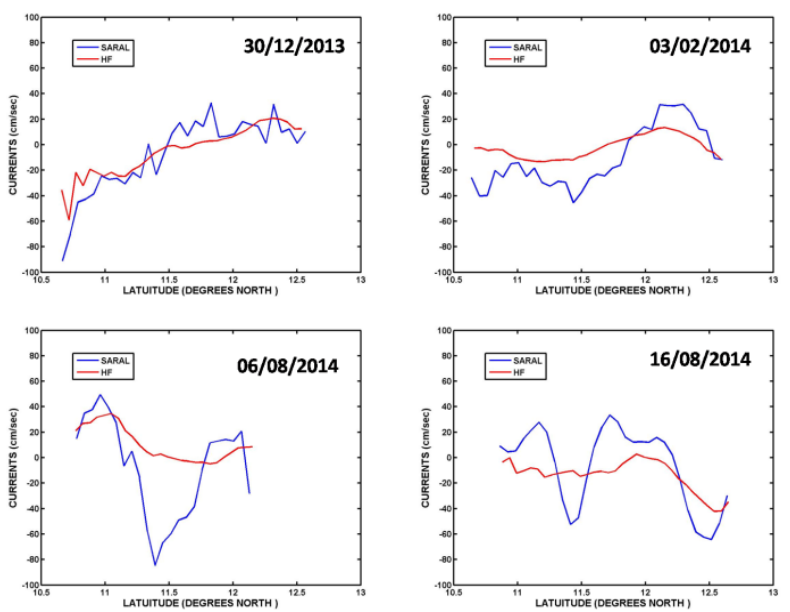

Figure.3 Latitudinal variation of HF radar velocity component (red line) plotted along with the geostrophic velocity from AltiKA (blue line) over the tracks as shown in Figure.2

Figure. 3 show the along track velocity plots corresponding to the tracks that are shown in Figure-2 from HF radar and SARAL AltiKA. It can be clearly seen that the latitudinal variation of the velocity component from SARAL is in agreement with the HF radar observations. The altimeter currents seem to have much more fluctuations indicating submesoscale variation. There are, however larger oscillations seen in the altimeter derived current specifically during the month of August between $11 \mathrm{~N}$ and $11.5 \mathrm{~N}$ and the further north between $12 \mathrm{~N}$ and $12.5 \mathrm{~N}$ when the currents from altimeter show a change in direction as well large change in magnitude. These oscillations are quite damped in the HF radar velocity component. Whether it is a noise in the altimeter or it is the missing Ekman contribution (which may be large during this period of time because of south west monsoon winds) is yet to be ascertained.

\section{CONCLUSION}

In this study the across track surface geostrophic currents obtained from along track SARAL altimeter data are directly compared (qualitatively) with high frequency (HF) radar observations of surface currents in the Bay of Bengal. The velocity component from HF radar which is perpendicular to the altimeter tracks is considered. Since the ageostrophic velocity contribution is ignored for the moment, the surface geostrophic currents SARAL compare well only under low wind conditions. Due to high along track resolution of SARAL there are large variations in velocity which are not captured by the HF radar observations. In general, the magnitude and variations in surface currents derived from SARAL altimeter are comparable with $\mathrm{HF}$ radar observations. In future we intend to apply more sophisticated methods of filtering out the noise from altimeter
SSHA. Additionally the ageostrophic contribution from HF radar currents would also be removed for better comparison.

\section{ACKNOWLEDGEMENTS}

The authors would like to thank Shri A. S. Kiran Kumar, Director, Space Applications Centre, Dr. P. K. Pal, Deputy Director, Earth Ocean Atmosphere Planetary Sciences and Applications Area, SAC and Dr. Raj Kumar, Group Director, Atmospheric and Oceanic Sciences Group for their encouragement and motivation. We sincerely acknowledge Indian National Centre for Ocean Information Services, Hyderabad for providing us with HF Radar data.

\section{REFERENCES}

Brown, G, 1977. The average impulse response of a rough surface and its applications, IEEE Trans.AntennasPropag., 25(1), pp. 67-74.

Fu,L., Cazenave,A., 2001. Satellite Altimetryand Earth Sciences, A Handbook of Techniques and Applications, International Geophysics Series, 69, Academic Press, San Diego, Calif.

Johnson, E., S., Bonjean, F., Lagerloef, G.,S.,E., Gunn, J.,T., Mitchum, G.,T.,2007. Validation and error analysis of OSCAR Sea-surface currents. J.Atmos. Oceanic Technol. 24 (4), pp.688701 ,

Sikhakolli, R., Sharma, R., Raj Kumar, Gohil, B.,S., Sarkar, A., Prasad, K.,V.,S.,R., and Basu, S, 2013, Improved determination of Indian Ocean surface currents using satellite data, Remote Sens. Lett., Vol 4(4), pp. 335-343. 